\title{
Elements of psychocardiology in the psychosocial handling of adults with congenital heart disease
}

\section{Edward Callus*, Emilia Quadri and Massimo Chessa}

Department of Pediatric Cardiology and Adult with Congenital Heart Defect, IRCCS Policlinico San Donato, San Donato Milanese, Italy

\section{Edited by:}

Francesco Pagnini, University of

Bergamo, Italy

Reviewed by:

Lara Bellardita, Università Cattolica del

Sacro Cuore, Italy; IRCCS Istituto

Nazionale dei Tumori, Italy

Francesco Pagnini, University of

Bergamo, Italy

\section{*Correspondence:}

Edward Callus, Department of Pediatric

Cardiology and Adult with Congenital

Heart Defect, IRCCS Policlinico San

Donato, Viale Morandi, 30, 20097 San

Donato Milanese, Italy.

e-mail:edward.callus@gmail.com
When it comes to the role of the clinical psychology in the cardiac settings, or psychocardiology, there is often a focus on acquired cardiac illnesses in the rehabilitation settings. However, the increase of adults with congenital heart disease due to technological advances in cardiology and cardiac surgery have created a new emergency. It is thus necessary to reflect upon the elements of psychocardiology adapting them to this new population, also when it comes to interventional hospital settings of cardiology and cardiac surgery. This perspective article is an effort in this direction.

Keywords: adults, congenital heart disease, clinical psychology, psychocardiology

\section{CONGENITAL HEART DISEASE: INCIDENCE, PSYCHOSOCIAL ASPECTS AND LIFE EXPERIENCES}

Congenital heart disease (ConHD) is the most common inborn defect, with an approximate prevalence of eight newborns for every 1000 births; this incidence has remained stable for the last 50 years and it does not vary across countries (Hoffman and Kaplan, 2002). Previously these patients used to carry a very poor prognosis, however nowadays most of them survive reaching adulthood. In fact, the number of adults with congenital heart disease (ACHD) is growing rapidly due to the advances and triumphs of cardiovascular medicine and surgery in the 20th century (Gatzoulis et al., 2005); the growth rate has been estimated to be $5 \%$ per year (Brickner et al., 2000).

In the population of these patients, one third is considered to have a simple condition, however the majority have lesions of great complexity. Most of them will also have lifelong ongoing ConHD and other medical needs (Gatzoulis et al., 2005). In fact, more than a third of the patients is born with "critical heart disease" involving life threatening malformations which necessitate palliative or corrective surgery in early life (Samanek, 2000; Marino et al., 2001).

For this reason, ongoing treatment demands have been identified as having an effect on the quality of life (QoL) of ACHD, together with possible complications in pregnancy and physical limitations and restrictions, which can be both real and imaginary. Having a ConHD most often causes some difficulties when it comes to peer relationships and employment, especially in adolescence and young adulthood, mostly because there is a delay in the maturation progress due to having to cope with the condition, besides the other developmental tasks (Kovacs et al., 2005).

Being an invisible disability, ACHD patients often report that their family and friends imply that the problems they have do not really exist and that changes in work or household responsibilities are not really necessary. These patients might also have problems at work as their requests can be met with skepticism or accusations of dishonesty (Verstappen et al., 2006).
One of the main problems outlined by the literature and which we also encountered in our clinical experience is that the understanding of what ConHD conditions actually entail often result to be problematic for the patients and their relatives (Chessa et al., 2005; Moons et al., 2005). This is probably due to the fact that many factors, such as cardiac malformation, physical functionality, and previous interventions need to be considered.

There are currently very few studies which take into consideration the direct experiences of ACHD patients themselves, even though these are crucial in order to be able to adequately counsel these patients and their families in order to promote QoL (Claessens et al., 2005). No specific psychosocial outcomes referring to patients born with the same pathology have been found; patients having the same conditions can have widely varied experiences depending on many biopsychosocial variables, such as the type of treatment received and their social support network. However there appear to be some patterns of experience and perspective in this broad diversity (Verstappen et al., 2006).

In fact the theme of being different from healthy peers emerges in the literature concerning adults followed by attempts and struggle to feel normal and to be perceived as being normal by others (Gantt, 1992, 2002; Claessens et al., 2005; Berghammer et al., 2006; Verstappen et al., 2006). This feeling can also result in ambivalence and also denial of the condition and efforts to exceed physical boundaries (Berghammer et al., 2006).

\section{THE NECESSITY FOR THE HUMANIZATION OF HEALTHCARE IN ACHD}

In the last decade there has been a greater attention to the experience of patients receiving healthcare. Although technological progress has brought many benefits, it has also entailed the risk of potentially developing less personal and less humanized processes, systems and institutions (Todres et al., 2007). 
ConHD patients and their relatives necessitate a lot of support because of many factors; uncertainty, frequent hospitalizations, restrictions, and difficulties in work and social spheres as mentioned previously (Kovacs et al., 2005; Verstappen et al., 2006). In an increasing number of qualitative research studies, the need for a more humanized approach to treatment is emerging (Todres et al., 2000; Galvin et al., 2005) and this need also emerges in the literature on ACHD.

In particular, in one study (Kools et al., 2002), the hospitalization experiences of ACHD patients were examined, from multiple points of view; including also the ones of the patients' families and the nurses during acute phases of their illness. The authors highlight the fact that each groups had different expectations about the management of the physical needs and about the way the patients and the patients' families behaved and that this caused interpersonal conflict, distrust, anxiety, and dissatisfaction with the healthcare provided.

The patients report on how equipment appropriate for adults was not always available or considered, that they were sometimes treated in a condescending way, scared of unfamiliar treatment protocols, and they felt that they were not listened to when they tried to make some observations about their health.

In another article the authors report quotations from the Adult Congenital Heart Association in order to address the patients' perspectives (Verstappen et al., 2006) outlining the implications for care. The following section is a summary of the most important issues which emerged combined with other literature.

Patients being told they were "miracle babies" and also at the other end, lost causes, that they would not survive for long, erroneously. When the patients believed that they were lost causes they sometimes engaged in highly risky behavior because they did not believe they had a future to put at risk, and they also had difficulty to move into adulthood since they were not expecting to make it so far.

There is a risk of language based misperception in understanding if the condition is completely cured or not in the conditions of moderate and great complexity. As mentioned previously, few patients have the knowledge and understanding to enact behaviors to safeguard and optimize their health (Moons et al., 2001; Chessa et al., 2005) and this could also occur because some healthcare providers have attitudinal barriers to educate the patients on risks associated with the condition and the need for lifelong follow-up. Also the patients' behaviors can contribute to a lack of knowledge as outlined previously.

Adult patients also commonly report that they have difficulties when they have to go to the "regular" medical system, where the medical personnel is not specialized in ConHD. They often report the need to be vigilant in order to reject medications which could be inappropriate for them, prescribed by the primary care providers and that insisting for special care can result in hostility.

Other difficult situations the patients have to face are making difficult decisions regarding treatment, referral for surgery and being informed that there is nothing left to be done (Horner et al., 2000). Sometimes information is withheld from the patients and they get to know about their real condition at the onset of new problems, making it particularly hard for them to adapt, also because of feelings of betrayal and anger.

\section{ELEMENTS OF PSYCHOCARDIOLOGY IN THE PSYCHOSOCIAL HANDLING OF ACHD PATIENTS}

Psychocardiology is not intended to be a new discipline on its own but rather, it is an effort to see how psychology can contribute in the prevention, treatment, and rehabilitation of patients with cardiac disease (Molinari et al., 2006). In this perspective, psychological and cardiac issues are not seen separately and there is a belief that a multidisciplinary approach is necessary for the wellbeing of the cardiac patient. It is also necessary that the knowledge and skills derived from training in clinical psychology to be tailored to the needs of cardiac patients, and also to cardiac patients with different diseases as different cardiac conditions also have different implications.

In fact it is important to make a distinction between ConHD and acquired cardiac illness; this population is much younger, and as stated before the adult population is always on the increase; in fact there are more adults than children living with ConHD (Webb, 2005). Several authors have already emphasized the importance of recognizing and managing the potential psychosocial consequences of growing up with ConHD (Moons et al., 2002; Kovacs et al., 2005) and international working groups have also outlined the necessity of including specialized mental healthcare for ACHD patients (Connelly et al., 1998; American College of Cardiology, 2001a,b; Deanfield et al., 2003).

Despite these recommendations it seems that the under-diagnosis and under-treatment of psychosocial concern are present in ACHD patients (Bromberg et al., 2003); for this reason it is important to include a psychologist in ACHD teams. Kovacs et al. (2006) have specified that there are three factors which affect the possible involvement of a psychologist in an ACHD team; the commitment of the specific institution to the psychosocial concerns of this population; an adequate size of the ACHD program; and the availability of psychologists who have specialized cardiac experience.

As already specified many patients have difficulties in grasping their condition so it is important to initiate proactive discussions. Trying to avoid important topics will harm the patient in the long run, and initiating discussions allows them to feel they can ask questions and that what they are going through is common. It is important to enact an adequate screening system in hospital settings, in order to detect and manage psychosocial issues: Kovacs et al. (2005) suggests employing the 4 A's;

a. Ask the patient about specific challenges,

b. Advise the patient on common challenges and how to manage them,

c. Assist the patient through psychological interventions such as support and brief problem solving, and

d. Arrange referral when the patient is evaluated as needing a mental health specialist.

Referrals to psychologists can be initiated by the patient or the physician. Sometimes ACHD patients enquire themselves if a psychologist is available, at other times the physicians broach the topic with their patients. It is always important that a psychological (or even a psychiatric) referral is made with the patient's knowledge. It is essential to clarify appropriate referral indications with the psychologists working with an ACHD team (Kovacs et al., 2006). 
Referral to other specialists such as psychiatrists (Bassett et al., 2005) and experts in substance abuse (especially since has been linked to unsuccessful transitioning from pediatric to adult care; Reid et al., 2004) could be necessary in particular cases.

Currently there is no specific training program in the field of psychocardiology, however some theoretical and methodological approaches typical of clinical psychology could form part of a good theoretical framework for this field (Molinari et al., 2006). These theoretical frameworks will now be described with reference to the psychosocial handling of ACHD.

\section{PATIENT FOCUSED THERAPY}

Carl Rogers developed the concept idea of "patient focused therapy" (Raskin and Rogers, 1989). He believed that the client only needed three things from a clinician to experience therapeutic improvement - congruence, unconditional positive regard, and empathetic understanding (McMillan, 2004). This theoretical framework emphases the fact that the clients have the necessary resources to reach their full potential and that therefore the psychologist should assume a non-directive stance. Surely these qualities can help the cardiac patient to open up and increase therapeutic compliance, however sometimes a more directive approach is necessary due to particular patients and contextual and temporal limitations.

As outlined by the literature ACHD patients have to overcome a lot of difficulties, and many of them have a very hard time during hospitalization due to a variety of factors; their health condition, their family and possible problems with the sanitary personnel (Kools et al., 2002; Kovacs et al., 2005).

Often the patients have to undergo heavy interventions, make difficult decisions, adjust to abrupt changes in their health and also withstand uncertainty. Patients can also feel angry if they suddenly get worse after many years of relative stability (Horner et al., 2000).

Some patients also learn about their condition in adulthood and could have a hard time adjusting to this. It is also possible that the patients of this population have an increased awareness of mortality and that therefore they need support in order to deal with anticipatory grief and working on strategies to communicate effectively with relatives and sanitary personnel (Kovacs et al., 2006).

It is therefore important to provide support to these patients and this type of therapy supplies the clinician with instruments which help the patient to open up and feel relief. The therapeutic techniques which are typical of this type of therapy are useful especially when first contacting the patient, in order to create a good working alliance and also when the patient is passing through hard times, therefore before the interventions and during their stay in the intensive therapy unit when they are feeling helpless.

\section{POSITIVE PSYCHOLOGY}

Positive psychology is the scientific study of human happiness and well-being. Its focus is the increase of the positive experience of life through optimism and the development of personal traits like courage, perseverance, and altruism (Linley et al., 2006). In this field there is an emphasis on the role of individual resources and abilities, instead of focusing on what is wrong and dysfunctional; in fact this field has also encouraged an increasing interest in research on coping (Livneh and Martz, 2007). Its main contribution in psychocardiology is the promotion of QoL for patients and their family members.

One of the major difficulties in ConHD patients is their transition from adolescence to adulthood; many adolescents who do not manage to successfully transition to adult care (Reid et al., 2004). The literature also outlines the patients' difficulties with employment and health insurance (Fekkes et al., 2001; Kamphuis et al., 2002; van Rijen et al., 2003) which could lead to depression (Popelova et al., 2001). It is therefore important to keep in mind the resources these patients have and not to focus too much on what is wrong, and to utilize strategies such as empowerment (Kovacs et al., 2006).

In a research carried out by Moons et al. (2005) the most important determinants of an ACHD, QoL resulted as being dependent upon family, job/education, friends, health, and leisure time, therefore it is important to investigate these areas, and potentiate as much as possible the resources already available, in order to increase QoL and to allow the implementation of functional coping strategies. Too often in a hospital setting there is too much focus on what is wrong, not giving the right importance to potentiate the resources already present in order to ensure a good rehabilitation process and medical adherence.

Finally it is also important to emphasize that there are not only negative consequences but also benefits that patients derive from surviving a ConHD condition; these include treats from their family because they had to endure great difficulties, receiving special attention, increased resilience and maturity and a clearer sense of their vocations. The ongoing awareness of one's mortality can lead to an increased appreciation of life, more clarity of purpose, and better decision making (Mathieu, 2005).

\section{COGNITIVE-BEHAVIORAL THERAPY}

The main goal of many cognitive-behavioral therapies is to find out and identify the biased, dysfunctional ways of relating and reacting of the clients and to help them transcend these in ways that will lead to increased well-being through different methodologies (Beck et al., 2007). The main elements of the therapeutic process in this model are:

a. The definition of how and when dysfunctional behavior is enacted;

b. Identifying any ineffective strategies utilized to face the problematic situation;

c. Discovering and utilizing problem or emotion oriented effective strategies (coping strategies) (Meichenbaum, 1997).

This therapeutic model/framework is particularly useful when treating cardiac patients because usually the intervention is brief and focused and both patient and therapist play an active role in setting goals and in identifying specific cognitive patterns that may generate problems. For this reason it could be useful to try to reduce risk factors and unhealthy behaviors, although the working alliance must always be taken into consideration in order not to provoke resistance in these patients. This might occur especially if the psychologist adopts a "psycho-educational" stance, focusing on the problems and not taking into consideration the patients' perspectives (Molinari et al., 2006). 
Although a non-directive stance is useful to help the patient open up and to provide support, often in the hospital setting it is necessary to reach certain objectives, such as evaluating a patient and working on therapeutic alliance. It is possible that for some patients encouragement and support are enough however some others will need a more direct approach which includes behavioral strategies in order to maximize adherence.

Some cognitive-behavioral techniques are particularly indicated for some problems which this population present, these include increased sensitivity to heart-focused anxiety and bodily sensations (Utens et al., 1998; Eifert et al., 2000; Rietveld et al., 2004) communication problems with family, peers, and sanitary personnel, getting used to new cardiac devices and also pre-interventional anxiety. The techniques which could be of used are autogenic training, progressive relaxation and social skills training (Sears Jr. et al., 1999; Sears et al., 2004; Seskevich et al., 2004; Kovacs et al., 2006).

It is possible that some patients have difficulty with the implantation of cardiac devices such as the implantable cardiac defibrillator (ICD), especially if they are young (Sears Jr. et al., 1999), and cognitivebehavioral strategies have been shown to be useful to enhance the confidence and QoL of ICD recipients (Sears et al., 2004). Psychological factors can have a negative impact on surgical recovery (Kiecolt-Glaser et al., 1998) and some meta-analytical studies have demonstrated that psychological and psycho-educational preparation for surgery can have a positive impact on surgery outcomes (Devine, 1992; Johnston and Vogele, 1993). Psychologists can provide preparation techniques which improve the reduction of anxiety in cardiac patients which have to undergo a surgical procedure (Seskevich et al., 2004);

It is especially important for cardiac disease patients to take care of their diet, to exercise appropriately and not to indulge in risky health behaviors which can compromise their health. Psycho-education seems to be helpful with it comes to lifestyle behaviors in patients with coronary heart disease (Dusseldorp et al., 1999) although there are no specific studies regarding this in ACHD patients. These patients seem to engage less in physical activity (Reybrouck and Mertens, 2005) and behavioral strategies could be utilized to adopt and maintain physician approved physical activity regimens and also to adhere to the physician's recommendations.

\section{SYSTEMIC FAMILY THERAPY}

In this model the central focus tends to be on interpersonal dynamics, especially in terms of how change in one person will affect the entire system (Bitter and Corey, 2001). The occurrence of any destabilizing event, including the diagnosis of a cardiac diagnosis or any other serious illness causes a break down in the existing family system. This model is useful when the family system does not manage to re-establish a "homeostasis" after a cardiac event, with the consequence of increasing emotional distress and conflict resulting directly or indirectly in a lower QoL for the patient's family and a stress on the patient's medical and psychological condition (Molinari et al., 2006).

The fact that some patients' parents can be overprotective has been underlined in the literature (Brandhagen et al., 1991; Gantt, 1992) and this could cause these patients to develop and maintain dependent lifestyles (Kokkonen and Paavilainen, 1992) even though the situation seems to improve as they grow up (Fox, 2002).

The family plays a very important role in the psychological functioning and the QoL of these patients; both overprotection and neglect could lead to the adoption of maladaptive coping strategies. Systemic family therapy can be useful in order to assess how the family adjusts to the illness and it can suggest ways to improve coping and help patients to transition more efficiently into adulthood.

\section{CONCLUSION}

Besides the importance of the psychologist when it comes to the clinical services in the handling of these patients, Kovacs et al. (2006) indicated the psychologists can also help the ACHD team when it comes to multidisciplinary research and professional education.

Many different instruments were utilized to measure psychological constructs in this population, and there is a need for the creation of specific psychosocial measures (American College of Cardiology, 2001a; Deanfield et al., 2003). There already have been some attempts in this direction (Kamphuis et al., 2004), although additional measures are required in order to address the unique concerns of this population, as the psychosocial measures developed for acquired cardiac disease do not capture the full ACHD patient experience (Kovacs et al., 2006).

Currently, there are few of these studies present in the literature and more are required to understand how the population deals with the various issues through time. Also no trials yet exist when it comes to psychological interventions for ACHD patients (Lip et al., 2003) and since there are few specialized centers it is also feasible to think about how to provide long distance support and how to evaluate it (American College of Cardiology, 2001a).

Finally psychologists can provide insights on the effectiveness of medical interventions by exploring how the patients feel before and after they are carried out, especially in the domains of QoL and psychological functioning. It is also important to assess how psychological factors could possibly influence physical functioning in this population.

\section{REFERENCES}

American College of Cardiology. (2001a). Care of the adult with congenital heart disease. Presented at the 32nd Bethesda conference, Bethesda, Maryland, October 2-3, 2000. J. Am. Coll. Cardiol. 37, 1161-1198.

American College of Cardiology. (2001b). Summary of recommendations - care of the adult with congenital heart disease. J. Am. Coll. Cardiol. 37, 1167-1169.

Bassett, A. S., Chow, E. W., Husted, J. Weksberg, R., Caluseriu, O., Webb, G. D., and Gatzoulis, M. A. (2005). Clinical features of 78 adults with 22q11 deletion syndrome. Am. J. Med. Genet. A 138, 307-313.
Beck, A., Davis, D., and Freeman, A. (2007). Cognitive Therapy of Personality Disorders, 2nd Edn. New York: Guilford Press.

Berghammer, M., Dellborg, M., and Ekman, I. (2006). Young adults experiences of living with congenital heart disease. Int. J. Cardiol. 110, 340-347.
Bitter, J., and Corey, G. (2001). "Family systems therapy," in Theory and Practice of Counseling and Psychotherapy, ed. G. Corey (Belmont, CA: Brooks/Cole), 382-453.

Brandhagen, D. J., Feldt, R. H., and Williams, D. E. (1991). Long-term psychologic implications of congenital heart disease: a 25-year 
follow-up. Mayo Clin. Proc. 66, 474-479.

Brickner, M. E., Hillis, L. D., and Lange, R. A. (2000). Congenital heart disease in adults. First of two parts. N. Engl. J. Med. 342, 256-263.

Bromberg, J. I., Beasley, P. J., D’Angelo, E. J., Landzberg, M., and DeMaso, D. R. (2003). Depression and anxiety in adults with congenital heart disease: a pilot study. Heart Lung 32, 105-110.

Chessa, M., De Rosa, G., Pardeo, M., Negura, G. D., Butera, G., Feslova, V., Piazza, L., Giamberti, A., Bossone, E., and Carminati, M. (2005). Illness understanding in adults with congenital heart disease. Ital. Heart J. 6 , 895-899.

Claessens, P., Moons, P., de Casterle, B. D., Cannaerts, N., Budts, W., and Gewillig, M. (2005). What does it mean to live with a congenital heart disease? A qualitative study on the lived experiences of adult patients. Eur. J. Cardiovasc. Nurs. 4, 3-10.

Connelly, M.S., Webb, G. D., Somerville, J., Warnes, C. A., Perloff, J.K., Liberthson, R. R., Puga, F. J., Collins-Nakai, R. L., Williams, W. G., Mercier, L.A., Huckell, V.F., Finley, J.P., and McKay, R. (1998). Canadian consensus conference on adult congenital heart disease 1996. Can. J. Cardiol. 14, 395-452.

Deanfield, J., Thaulow, E., Warnes, C., Webb, G., Kolbel, F., Hoffman, A., Sorenson, K., Kaemmer, H., Thilen, U., Bink-Boelkens, M., Iserin, L., Daliento, L., Silove, E., Redington, A., Vouhe, P., Priori, S., Alonso, M. A., Blanc, J. J., Budaj, A., Cowie, M., Deckers, J., Fernandez, B. E., Lekakis, J., Lindahl, B., Mazzotta, G., Morais, J., Oto, A., Smiseth, O., Trappe, H. J., Klein, W., Blomstrom-Lundqvist, C., de Backer, G., Hradec, J., Parkhomenko, A., Presbitero, P., and Torbicki, A. (2003). Management of grown up congenital heart disease. Eur. Heart J. 24, 1035-1084.

Devine, E. C. (1992). Effects of psychoeducational care for adult surgical patients: a meta-analysis of 191 studies. Patient. Educ. Couns. 19, 129-142.

Dusseldorp, E., van Elderen, T., Maes, S., Meulman, J., and Kraaij, V. (1999). A meta-analysis of psychoeducational programs for coronary heart disease patients. Health Psychol. 18, 506-519.

Eifert, G. H., Zvolensky, M. J., and Lejuez, C. W. (2000). Heart-focused anxiety and chest pain: a conceptual and clinical review. Clin. Psychol. Sci. Pract. 7, 403-417.

Fekkes, M., Kamphuis, R. P., Ottenkamp, J., Verrips, E., Vogels, T., Kamphuis, M., and Verloove-Vanhorick, S. P. (2001). Health-related quality of life in young adults with minor congenital heart disease. Psychol. Health 16, 239-250.

Fox, A. (2002). Physicians as barriers to successful transitional care. Int. J. Adolesc. Med. Health 14, 3-7.

Galvin, K., Todres, T., and Richardson, M. (2005). The intimate mediator: A carer's experience of Alzheimer's. Scand. J. Caring. Sci. 19, 2-11.

Gantt, L. (2002). As normal a life as possible: mothers and their daughters with congenital heart disease. Health Care Women Int. 23, 481-491.

Gantt, L. T. (1992). Growing up heartsick: the experiences of young women with congenital heart disease. Health Care Women Int. 13, 241-248.

Gatzoulis, M.A., Swan, L., Therrien, J., and Pantely, G.A. (2005). Adult Congenital Heart Disease: A Practical Guide. Oxford: Blackwell Publishing.

Hoffman, J. I., and Kaplan, S. (2002). The incidence of congenital heart disease.J. Am. Coll. Cardiol. 39, 1890-1900.

Horner, T., Liberthson, R., and Jellinek, M. S. (2000). Psychosocial profile of adults with complex congenital heart disease. Mayo Clin. Proc. 75, 31-36.

Johnston, M., and Vogele, C. (1993). Benefits of psychological preparation for surgery: a meta-analysis. Ann. Behav. Med. 15, 245-256.

Kamphuis, M., Vogels, T., Ottenkamp, J., Van Der Wall, E. E., VerlooveVanhorick, S. P., and Vliegen, H. W. (2002). Employment in adults with congenital heart disease. Arch. Pediatr. Adolesc. Med. 156, 1143-1148.

Kamphuis, M., Zwinderman, K. H., Vogels, T., Vliegen, H. W., Kamphuis, R. P., Ottenkamp, J., Verloove-Vanhorick, S. P., and Bruil, J. (2004). A cardiac-specific health-related quality of life module for young adults with congenital heart disease: development and validation. Qual. Life Res. 13, 735-745.

Kiecolt-Glaser, J.K., Page, G. G., Marucha, P. T., MacCallum, R. C., and Glaser, R. (1998). Psychological influences on surgical recovery. Perspectives from psychoneuroimmunology. Am. Psychol. 53, 1209-1218.

Kokkonen, J., and Paavilainen, T. (1992). Social adaptation of young adults with congenital heart disease. Int. J. Cardiol. $36,23-29$.

Kools, S., Tong, E. M., Hughes, R., Jayne, R., Scheibly, K., Laughlin, J., and Gilliss, C. L. (2002). Hospital experiences of young adults with congenital heart disease: divergence in expectations and dissonance in care. Am. J. Crit. Care 11, 115-125; quiz 126-117.

Kovacs, A. H., Sears, S. F., and Saidi, A. S. (2005). Biopsychosocial experiences of adults with congenital heart disease: review of the literature. Am. Heart J. 150, 193-201.
Kovacs, A. H., Silversides, C., Saidi, A., and Sears, S. F. (2006). The role of the psychologist in adult congenital heart disease. Cardiol. Clin. 24, 607-618, vi.

Linley, A. P., Joseph, S., Harrington, S., and Wood, A. M. (2006). Positive psychology: past, present, and (possible) future. J. Posit. Psychol. 1, 3-16.

Lip, G. Y., Lane, D. A., Millane, T. A., and Tayebjee, M. H. (2003). Psychological interventions for depression in adolescent and adult congenital heart disease. Cochrane Database Syst. Rev. CD004394.

Livneh, H., and Martz, E. (2007). "An introduction to coping theory and research," in Coping with Chronic Illness and Disability, Theoretical, Empirical, and Clinical Aspects, eds E. Martz and H. Livneh (New York: Springer), 3-28.

Marino, B. S., Bird, G. L., and Wernovsky, G. (2001).Diagnosis and management of the newborn with suspected congenital heart disease. Clin. Perinatol. 28, 91-136.

Mathieu, P. (2005). What's Your Expiry Date? Ontario: Patrick Mathieu Unlimited.

McMillan, M. (2004). The Person-Centred Approach to Therapeutic Change. London/Thousand Oaks, CA: SAGE Publications.

Meichenbaum, D. (1997). "The evolution of a cognitive-behavior therapist," in The Evolution of Psychotherapy: The Third Conference, ed. J. K. Zeig (Philadelphia: Brunel/Mazzel Inc.), 95-104.

Molinari, E., Bellardita, L., and Compare, A. (2006). "Clinical psychology and heart disease," in Clinical Psychology and Heart Disease, eds E. Molinari, A. Compare, and G. Parati (Milan: Springer-Verlag Italia), 5-18.

Moons, P., De Geest, S., and Budts, W. (2002). Comprehensive care for adults with congenital heart disease: expanding roles for nurses. Eur. J. Cardiovasc. Nurs. 1, 23-28.

Moons, P., De Volder, E., Budts, W., De Geest, S., Elen, J., Waeytens, K., and Gewillig, M. (2001). What do adult patients with congenital heart disease know about their disease, treatment, and prevention of complications? A call for structured patient education. Heart 86, 74-80.

Moons, P., Van Deyk, K., De Geest, S., Gewillig, M., and Budts, W. (2005). Is the severity of congenital heart disease associated with the quality of life and perceived health of adult patients? Heart 91, 1193-1198.

Moons, P., Van Deyk, K., Marquet, K., Raes, E., De Bleser, L., Budts, W., and De Geest, S. (2005). Individual quality of life in adults with congenital heart disease: a paradigm shift. Eur. Heart J. 26, 298-307.

Popelova, J., Slavik, Z., and Skovranek, J. (2001). Are cyanosed adults with congenital cardiac malformations depressed? Cardiol. Young 11, 379-384.

Raskin, N. J., and Rogers, C. R. (1989). "Person-centered therapy," in Current Psychotherapies, 4th Edn., eds R. J. Corsini and D. Wedding (Chicago, IL: Peacock Publishers Inc.), 155-194.

Reid, G. J., Irvine, M. J., McCrindle, B. W., Sananes, R., Ritvo, P. G., Siu, S. C., and Webb, G. D. (2004). Prevalence and correlates of successful transfer from pediatric to adult health care among a cohort of young adults with complex congenital heart defects. Pediatrics 113(Pt 1), e197-e205.

Reybrouck, T., and Mertens, L. (2005). Physical performance and physical activity in grown-up congenital heart disease. Eur. J. Cardiovasc. Prev. Rehabil. 12, 498-502.

Rietveld, S., Karsdorp, P. A., and Mulder, B. J. (2004). Heartbeat sensitivity in adults with congenital heart disease. Int. J. Behav. Med. 11, 203-211.

Samanek, M. (2000). Congenital heart malformations: prevalence, severity, survival, and quality of life. Cardiol. Young 10, 179-185.

Sears, S. F. Jr., Todaro, J. F., Lewis, T. S., Sotile, W., and Conti, J. B. (1999). Examining the psychosocial impact of implantable cardioverter defibrillators: a literature review. Clin. Cardiol. 22, 481-489.

Sears, S. F., Kovacs, A. H., Azzarello, L., Larsen, K., and Conti, J. B. (2004). Innovations in health psychology: the psychosocial care of adults with implantable cardioverter defibrillators. Prof. Psychol. Res. Pract. 35, 520-526.

Seskevich, J. E., Crater, S. W., Lane, J. D., and Krucof, M. W. (2004). Beneficial effects of noetic therapies on mood before percutaneous intervention for unstable coronary syndromes. Nurs. Res. 53, 116-121.

Todres, L., Fulbrook, P., and Albarran, J. (2000). On the receiving end: a hermeneutic-phenomenological analysis of a patient's struggle to cope while going through intensive care. Nurs. Crit. Care 5, 277-287.

Todres, L., Galvin, K., and Dahlberg, K. (2007). Lifeworld-led healthcare: revisiting a humanising philosophy that integrates emerging trends. Med. Health Care Philos. 10, 53-63.

Utens, E. M., Bieman, H. J., Verhulst, F. C., Meijboom, F. J., Erdman, R. A. and Hess, J. (1998). Psychopathology 
in young adults with congenital heart disease. Follow-up results. Eur. Heart J. 19, 647-651.

van Rijen, E. H., Utens, E. M., RoosHesselink, J. W., Meijboom, F. J., van Domburg, R. T., Roelandt, J. R., Bogers, A. J., and Verhulst, F. C. (2003). Psychosocial functioning of the adult with congenital heart disease: a 20-33 years follow-up. Eur. Heart J. 24, 673-683.
Verstappen, A., Pearson, D., and Kovacs, A. H. (2006). Adult congenital heart disease: the patient's perspective. Cardiol. Clin. 24, 515-529, v.

Webb, G. (2005). Improving the care of Canadian adults with congenital heart disease. Can. J. Cardiol. 21, 833-838.

Conflict of Interest Statement: The authors declare that the research was conducted in the absence of any commercial or financial relationships that could be construed as a potential conflict of interest.

Received: 03 May 2010; paper pending published: 14 May 2010; accepted: 30 June 2010; published online: 11 August 2010.

Citation: Callus E, Quadri E and Chessa $M$ (2010) Elements of psychocardiology in the psychosocial handling of adults with congenital heart disease. Front. Psychology 1:34. doi: 10.3389/fpsyg.2010.00034
This article was submitted to Frontiers in Psychology for Clinical Settings, a specialty of Frontiers in Psychology.

Copyright (c) 2010 Callus, Quadri and Chessa. This is an open-access article subject to an exclusive license agreement between the authors and the Frontiers Research Foundation, which permits unrestricted use, distribution, and reproduction in any medium, provided the original authors and source are credited. 